\title{
Pure Laparoscopic Augmentation Ileocystoplasty
}

Rafael B. Rebouças ${ }^{1}$, Rodrigo C. Monteiro', Thiago N. S. de Souza'1, Augusto J. de Aragão', Camila R. T. Burity ${ }^{1}$, Júlio C. de A. Nóbrega ${ }^{1}$, Natália S. C. de Oliveira', Ramon B. Abrantes¹, Luiz B. Dantas Júnior ${ }^{1}$, Ricardo Cartaxo Filho', Gustavo R. P. Negromonte', Rafael da C. R. Sampaio', Cesar A. Britto ${ }^{1}$

${ }^{1}$ Faculty of Medical Sciences of Paraiba and Department of Urology, Police Military Hospital Edson Ramalho, João Pessoa, PB, Brazil

\section{ABSTRACT}

Introduction: Guillain-Barre syndrome is an acute neuropathy that rarely compromises bladder function. Conservative management including clean intermittent catheterization and pharmacotherapy is the primary approach for hypocompliant contracted bladder. Surgical treatment may be used in refractory cases to improve bladder compliance and capacity in order to protect the upper urinary tract. We describe a case of pure laparoscopic augmentation ileocystoplasty in a patient affected by Guillain-Barre syndrome.

Presentation: A 15-year-old female, complaining of voiding dysfunction, recurrent urinary tract infection and worsening renal function for three months. A previous history of Guillain-Barre syndrome on childhood was related. A voiding cystourethrography showed a pine-cone bladder with moderate post-void residual urine. The urodynamic demonstrated a hypocompliant bladder and small bladder capacity $(190 \mathrm{~mL})$ with high detrusor pressure $(54 \mathrm{cmH} 20)$. Nonsurgical treatments were attempted, however unsuccessfully.

The patient was placed in the exaggerated Trendelenburg position. A four-port transperitoneal technique was used. A segment of ileum approximately 15-20cm was selected and divided with its pedicle. The ileal anastomosis and creation of ileal U-shaped plate were performed laparoscopically, without staplers. Bladder mobilization and longidutinal cystotomy were performed. Enterovesical anastomosis was done with continuous running suture. A suprapubic cystostomy was placed through a $5 \mathrm{~mm}$ trocar.

Results: The total operative time was $335 \mathrm{~min}$. The blood loss was minimal. The patient developed ileus in the early days, diet acceptance after the fourth day and was discharged on the seventh postoperative day. The urethral catheter was removed after 2 weeks. At 6-month follow-up, a cystogram showed a significant improvement in bladder capacity. The patient adhered well to clean intermittent self-catheterization and there was no report for febrile infections or worsening of renal function. We did not experience any complication related to the intestinal anastomosis fully prepared intracorporeally.

Conclusions: Albeit technically challenging, pure laparoscopic enterocystoplasty was feasible and safe. Preparing the enteral anastomosis and the pouch intracoporeally may prolong surgical time and contribute to postoperative ileus. Surgical staplers can assist in the procedure, however they are not essential.

\section{ARTICLE INFO}

Available at: www.brazjurol.com.br/videos/november_december_2014/Reboucas_858_859video.htm

Int Braz J Urol. 2014; 40 (Video \#15): 858-9 
Submitted for publication:

October 04, 2014

Accepted after revision:

November 20, 2014
Correspondence address:

Rafael B. Rebouças, MD

Faculty of Medical Sciences of Paraiba

Department of Urology, Police Military Hospital Edson Ramalho, João Pessoa, Brazil

Email: rafael.reboucas@gmail.com

\section{EDITORIAL COMIMENT}

The video by Rebouças et al. nicely describes an augmentation ileocystoplasty performed entirely intracorporeally. This is a technically challenging surgery that requires advanced laparoscopic skills. When one contemplates performing more complex reconstructions laparoscopically, the potential benefits of laparoscopy must be weighed against the risks associated with prolonged operative times. Laparoscopic staplers and robotic assistance may help shorten surgical times, but they may also increase costs. Studies are currently underway to try to examine the results of intracorporeal urinary diversions. These investigations will help define the benefits and disadvantages of pure laparoscopic and robotic techniques (1).

\section{REFERENCE}

1. Ahmed K, Khan SA, Hayn MH, Agarwal PK, Badani KK, Balbay MD, et al. Analysis of intracorporeal compared with extracorporeal urinary diversion after robot-assisted radical cystectomy: results from the International Robotic Cystectomy Consortium. Eur Urol. 2014;65:340-7.

Hubert Swana, MD

Pediatric Urology Nemours Children's Hospital Orlando

Orlando, FL, USA

E-mail:hswana@nemours.org 